\title{
REFLEXÕES SOBRE OS IMPACTOS DA PANDEMIA DE COVID-19 NO ESPAÇO DOMÉSTICO
}

REFLECTIONS ON THE IMPACTS OF THE COVID-19 PANDEMIC ON DOMESTIC SPACE

Simone Barbosa Villa ${ }^{1}$, Gabriela Pereira Carneiro ${ }^{1}$, Rodrigo Araujo Moraes ${ }^{1}$, Nathalia Lya de Melo Carvalho ${ }^{1}$

\section{RESUMO:}

A pandemia da COVID-19 teve seu primeiro caso registrado no Brasil em meados de fevereiro de 2020. Desde então, o isolamento social foi considerado uma das ferramentas cruciais para seu enfrentamento. Parcela significativa da população teve que permanecer em casa e adaptar seus espaços para novas atividades, causando impactos nos modos de vida e consequente formas de morar. Neste contexto, o grupo [MORA] Pesquisa em Habitação da FAUED/UFU iniciou investigações acerca dos impactos da pandemia na habitação. As iniciativas fazem parte de um contexto maior de investigação sobre a Casa Resiliente e o desenvolvimento de instrumentos de avaliação pós-ocupação dos impactos e da resiliência - capacidade do ambiente construído e das pessoas de se adaptarem e responderem positivamente aos impactos ao longo do tempo. Esse artigo objetiva apresentar os principais resultados do questionário de impacto, centrado na COVID-19, aplicado de forma irrestrita e online a 468 moradores. Os resultados indicam seis principais aspectos da habitação nos quais o impacto da pandemia se faz presente de forma significativa. Observa-se a relação atual entre o exterior - contaminado e inseguro -, com o interior - considerado limpo e seguro, além de tensões estabelecidas no âmbito doméstico frente a adaptação de novas demandas e impactos oriundos da sobreposição de pessoas e atividades nas moradias. Mais do que nunca, questões necessárias como o espaço funcional, a ergonomia, a privacidade, a infraestrutura, a conectividade, a multifuncionalidade, a necessidade de estocagens e a flexibilidade se mostram de grande valia no momento diferente em que vivemos.

PALAVRAS-CHAVE: Avaliação pós ocupação; Impactos na habitação; Resiliência no ambiente construído.

\section{ABSTRACT:}

The COVID-19 pandemic had its first case recorded in Brazil in mid-February 2020.Since then, social isolation has been considered one of the crucial tool for tracking it. A significant portion of the population had to stay at home and adapt their spaces to new activities, causing impacts on ways of life and consequent ways of living. In this context, [MORA] H Neste contexto, o grupo [MORA] Housing Research of FAUeD/UFU initiated investigations about the impacts of the pandemic on housing. The initiatives are part of a larger research context on "Resilient Home" and the development of instruments for post-occupation evaluation of impacts and resilience - the capacity in the built environment and of people to adapt and respond positively to impacts over time. This article aims to present the main results of the impact questionnaire, centered on COVID-19, applied unrestrictedly and online to 468 residents. The results indicate six main aspects of housing, in which the impact of the pandemic is significantly present. The current relationship between the exterior contaminated and unsafe - is observed, with the interior - considered clean and safe, beside tensions established at the domestic level in the sense of adapting to the new demands and impacts arising from the overlapping of people and activities in the houses. More than ever, necessary issues such as functional space, ergonomics, privacy, infrastructure, connectivity, multifunctionality, the need for storage and flexibility are of great value in the different moment in which we live.

KEYWORDS: Post-occupancy Evaluation, Impacts on Housing, Resilience in the Built Environment.

How to cite this article:

VILLA, S. B.; CARNEIRO, G. P.; MORAES, R. A.; CARVALHO, N. L. M. Reflexões sobre o impacto da pandemia de COVID-19. Gestão \& Tecnologia de Projetos. São Carlos, v14, n4, 2021. https://doi.org/10.11606/gtp.v14i4. 176851
Fonte de Financiamento: Bolsa Produtividade PQ 2 CNPq; Bolsa de mestrado CAPES; PIBIC/CNPq/UFU.

Conflito de Interesse: Declaramos não haver conflintos de interesse.

Ética em Pesquisa: CEP de $n^{0}$ 20239019.5.0000.5152

Submetido em: 30/10/2020

Aceito em:

27/04/2021
ARTIGO

${ }^{1}$ Faculdade de e Design (FAUeD) da Universidade Federal de Uberlândia (UFU)

17685 


\section{INTRODUÇÃO}

Em 2019 o mundo foi surpreendido por uma pandemia viral, o novo coronavírus atingiu diretamente grande maioria da população mundial, impactando rigorosamente a moradia. Condicionados ao isolamento social, houve um aumento significativo da permanência das pessoas em suas casas, movimento que acarretou no surgimento de novos problemas e evidenciou outros já existentes nas habitações. 0 trabalho aqui apresentado se insere em um projeto de pesquisa maior intitulado "[BER HOME] Resiliência no ambiente construído em habitação social: métodos de avaliação tecnologicamente avançados"i , que objetiva avaliar os fatores que constituem a resiliência no ambiente construído em habitações sociais brasileiras identificando seus principais atributos projetuais. Desenvolvido no grupo de pesquisa

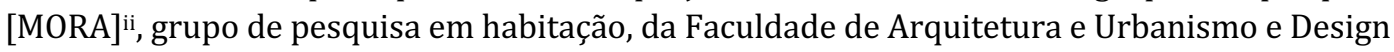
(FAUeD) da Universidade Federal de Uberlândia (UFU).

Com base nesta, foram estruturados instrumentosiii de Avaliação Pós-Ocupação (APO) visando a identificação dos impactos, vulnerabilidades e capacidades adaptativas incidentes na habitação no contexto da pandemia. A APO é um conjunto de procedimentos metodológicos avaliativos que visam a obtenção de dados consistentes relativos ao ambiente construído e a percepção dos seus usuários (MALLORY-HILL; PREISER; WATSON, 2012; VILLA e ORNSTEIN, 2013; VAN DER VOORDT e VAN WEGEN, 2013; COLE, 2005). Também inclui a identificação de impactos em que o meio está sujeito, suas fragilidades, recursos e potencialidades. A APO sistemática permite a montagem e observação de bancos de dados alimentados por avaliações que incluam a percepção física do ambiente construído e sua interação com o comportamento dos usuários (STEVENSON e LEAMAN, 2010; ONO et al., 2018; STEVENSON, 2019). Para a pesquisa aqui apresentada, foi utilizada uma ferramenta aprovada pelo Conselho de Ética em Pesquisa - CEP, protocolo de no 20239019.5.0000.5152, com 468 coletas.

Para discutir e complementar os resultados do questionário foi realizado pelo PPGAU (Programa de Pós-Graduação em Arquitetura e Urbanismo/UFU) um Workshop projetual online, iniciativa que reuniu de forma remota, ao longo de duas semanas, alunos da graduação e pós-graduação em arquitetura de diferentes instituições. As atividades propostas tiveram como intuito propor alternativas para habitação, a partir de pesquisas e reflexões sobre a forma como a atual pandemia causada pelo SARS-CoV-2 (vírus da Covid-19) tem afetado o cotidiano das pessoas e sua relação com o espaço interno de suas casas. Além das discussões e projetos propostos pelos grupos participantes, foi produzido um relatório finaliv como forma de registro das atividades, metodologia, discussões e propostas projetuais (VILLA et. al., 2020).

0 presente artigo tem como objetivo discutir os dados coletados e seus possíveis rebatimentos na arquitetura, refletindo sobre as problemáticas decorrentes do isolamento social imposto pela pandemia. Para tanto, os dados foram compilados em forma de gráficos e analisados textualmente, em conseguinte são apresentados os resultados na qualidade de provocações e reflexões. Espera-se assim, oferecer uma contribuição social e acadêmica, uma vez que esta pesquisa embasa com rigor futuros trabalhos sobre as questões aqui tratadas.

\section{CONTEXTUALIZAÇÃO}

As zoonoses são doenças infecciosas resultantes do contato humano com patógenos, organismos que causam doenças em hospedeiros, advindos de animais. Existem diferentes tipos de patógenos, tais como vírus, bactérias, fungos, protistas, príons e vermes. Quammen (2020) aponta que o vírus é o patógeno mais problemático, pois "eles evoluem depressa, não são afetados por antibióticos, podem ser difíceis de descobrir e versáteis, podem levar a taxas de mortalidade altíssimas e são diabolicamente simples, ao menos em comparação com outros 
seres vivos ou quase vivos". Encontram-se neste espectro nomes conhecidos tais como a gripe espanhola (1918-19), o ebola, a peste bubônica, gripe suína e aviária e a SARS. Segundo o autor, o crescimento exponencial da população mundial e a forma como a humanidade avança e se apropria da natureza, cria condições favoráveis para que diferentes tipos de zoonoses se espalhem.

A pandemia que tomou conta do mundo em 2020 veio do vírus zoonótico COVID-19 e teve início no final do ano de 2019 na cidade de Wuhan na China. Ao que tudo indica, trata-se de um vírus transmitido de morcegos para seres humanos (GRUBER, 2020) de forma que o primeiro caso de contaminação verificado no Brasil foi identificado em fevereiro de 2020. Trata-se de uma doença respiratória, em que aproximadamente $20 \%$ dos casos detectados precisam de atendimento hospitalar. 0 vírus é transmitido através do ar (principalmente por gotículas de saliva, espirro, tosse e contato com objetos e superfícies contaminadas), o que faz com que seja facilmente difundido no cotidiano das cidades (ORGANIZAÇÃO PAN AMERICANA DE SAÚDE, 2020).

A não existência de uma vacina ou remédio eficaz, fez com que restrições de funcionamento do comércio e medidas de isolamento social fossem tomadas a partir de março no Brasil, para evitar a circulação de pessoas. 0 distanciamento social foi a forma de retardar a velocidade de contágio da doença e evitar o colapso do sistema de saúde. Desta forma, evitar a propagação do vírus impôs a todas as pessoas condições que diminuíram o contato social e, para aquelas cuja condição socioeconômica permitiu (SANTOS, 2020), aumentaram o tempo de permanência em casa.

Esse contexto ressalta a complexidade da função social da habitação já que a coloca em direta relação com questões sanitárias e de saúde pública. Noções de privacidade foram colocadas em xeque diante da situação pandêmica atual, com muitas famílias condicionadas ao isolamento social, passando a vivenciar de forma integral suas residências e exercendo atividades de trabalho e estudos remotos. De forma abrupta, "as atividades da vida cotidiana passam a se realizar dentro da casa e não mais a partir da casa como o nó que liga e de onde se criam e se direcionam os fluxos cotidianos" (CARLOS, 2020, p.12). No geral, apesar do impacto acontecer de forma diferenciada em cada contexto habitacional, de alguma maneira a vida, o cotidiano e as percepções da vida urbana foram alteradas e consequentemente o papel da casa na vida das pessoas.

Falar sobre a adaptação da casa aos hábitos e protocolos decorrentes da necessidade de distanciamento social trazida pela COVID-19, é uma forma de explorar a noção de resiliência aplicada à habitação. A resiliência é entendida aqui, como a capacidade do ambiente construído e de seus usuários de responderem e se adaptarem aos impactos ao longo do tempo. Os impactos são o conjunto de choques agudos e estresses crônicos que ameaçam as vidas, meios de subsistência, saúde, ecossistemas, economias, culturas, serviços e infraestrutura de uma sociedade, além do ambiente construído expostos (GARCIA; VALE, 2017; HASSLER; KOHLER, 2014; VILLA et. al., 2017).

Os impactos podem ser considerados como ameaças potenciais que surgem de forma interrupta, em horizontes de tempo curtos, quanto como ameaças difusas e lentas em períodos mais longos. Os impactos incidentes sobre o meio urbano e seus sistemas são causados, a priori, por grandes causas ou desafios globais, com os quais os governos e a sociedade têm se deparado nos tempos atuais, chamando para si grande atenção. Assim, torna-se importante avaliar e conhecer os impactos incidentes no sistema, observando sua repercussão sobre o conjunto (Figura 1). Essa prática tem sido observada globalmente, com pesquisas que visam seu enfrentamento e a minimização dos efeitos negativos sobre o ambiente natural e construído (ARUP e THE ROCKEFELLER FOUNDATION, 2015; GARCIA \& VALE, 2017; ELIASTROSTMANN et al. 2018; LEMOS, 2014). Também se observa agendas urbanas relevantes, 
Figura 1. Elementos que compõem o Impacto Percebido nos Sistema Pesquisa BER-HOME

Fonte: PARREIRA (2019)

como a Nova Agenda Urbana - Habitat III (NEW URBAN AGENDA, 2017) e Sustainable Development Goals - AGENDA 2030 (SUSTAINABLE DEVELOPMENT GOALS, 2015), na qual a resiliência é definida como uma força motriz no combate ao estado vulnerável proporcionado pelo rápido crescimento da população urbana e outros problemas causados pela urbanização inadequada.

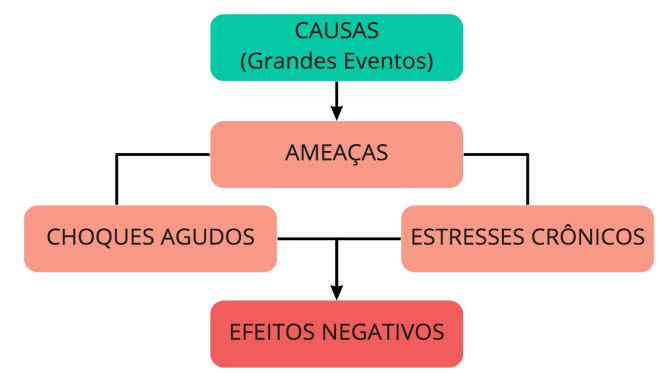

Não se sabe quanto tempo as condições de exceção impostas pela pandemia irão durar ou de que forma estes impactos irão reverberar no futuro. Isto posto, pesquisas que visem o entendimento e elaboração do momento presente são oportunidades de adicionar camadas de entendimento e reflexão sobre a adaptabilidade das pessoas e de sua relação com o espaço construído. Desta forma, a partir da elaboração de um questionário e de uma primeira análise dos dados, foram elencados seis principais aspectos da habitação nos quais o impacto da pandemia se faz presente de forma significativa. São eles: 0 trabalho e estudo em casa; os padrões de consumo e consciência ambiental; os novos usos hábitos de higiene, alimentares, etc.; a influência e necessidade da tecnologia; a relação com o entorno (cidade, bairro, vizinhos); noções de privacidade e interação.

O objetivo do artigo é explorar estes pontos a partir da análise das respostas obtidas, junto com outras ações realizadas, com o intuito de entender de forma fundamentada o impacto da COVID-19 na habitação. A apresentação desses principais aspectos foi também fruto do resultado de outras pesquisas realizadas pelo grupo [MORA] acerca da habitação contemporânea, suas principais características, qualidades e transformações, estudos esses, sempre amparados em fontes científicas nacionais e internacionais.

\section{METODOLOGIA}

Com o surgimento da pandemia de COVID-19 em fevereiro de 2019, o questionário de avaliação de impacto, desenvolvido para a pesquisa maior "[BER HOME] Resiliência no ambiente construído em habitação social: métodos de avaliação tecnologicamente avançados", foi adequado visando avaliar os impactos decorrentes da pandemia na habitação e nos modos de vida de seus moradores, notadamente em função da necessidade da permanência em casa. Seguindo a estrutura adotada na pesquisa geral, a pandemia foi considerada a "grande causa" e as ameaças foram identificadas como os atributos a serem avaliados em dois cenários: antes e durante a pandemia, com perguntas sobre informações gerais e 6 temas específicos: bemestar, engajamento, acessibilidade, flexibilidade, conforto ambiental e adequação ambiental (Quadro 1). 
SEÇÃO 1 - dados gerais - escalas de respostas variadas

\begin{tabular}{|c|c|}
\hline Sexo / Idade / Escolaridade & Quantidade de moradores \\
\hline Condição / tipo / localização de moradia & Renda mensal / Profissão \\
\hline Quantidade de cômodos & Área externa \\
\hline Grupo de risco e confirmação de COVID-19 & Medidas preventivas \\
\hline Situação atual de renda & $\begin{array}{l}\text { Tempo de permanência antes e durante o } \\
\text { isolamento }\end{array}$ \\
\hline \multicolumn{2}{|l|}{ Presença de moradores idosos } \\
\hline \multicolumn{2}{|c|}{$\begin{array}{c}\text { SEÇÃO } 2 \text { - nível de satisfação - comparativo antes e durante a pandemia - escala de respostas } \\
\text { padrão (4 + nsa) }\end{array}$} \\
\hline \multicolumn{2}{|c|}{ Tamanho e quantidade dos cômodos / n⿳o moradores } \\
\hline \multicolumn{2}{|c|}{ Tamanho e quantidade dos cômodos / usos } \\
\hline \multicolumn{2}{|c|}{$\begin{array}{c}\text { Adaptação dos cômodos para trabalhar/estudar/praticar exercícios /atividades de lazer/praticar } \\
\text { expressões artísticas }\end{array}$} \\
\hline \multicolumn{2}{|c|}{ Armazenamento de alimentos e produtos de limpeza / dos materiais de trabalho/estudo } \\
\hline \multicolumn{2}{|c|}{$\begin{array}{c}\text { Presença de mobiliários apropriados para trabalhar/estudar / de espaços e mobiliários apropriados } \\
\text { para crianças brincarem }\end{array}$} \\
\hline \multicolumn{2}{|c|}{ Quantidade de móveis / de banheiros } \\
\hline \multicolumn{2}{|c|}{$\begin{array}{l}\text { Presença de espaço para privacidade pessoal / adequados para higienizar objetos / de equipamentos } \\
\text { facilitadores da acessibilidade / armazenamento de lixo }\end{array}$} \\
\hline \multicolumn{2}{|c|}{ Localização de sua moradia } \\
\hline \multicolumn{2}{|c|}{ Barulho dentro da moradia / que vem de fora } \\
\hline \multicolumn{2}{|c|}{ Presença de luz natural / luz artificial } \\
\hline \multicolumn{2}{|c|}{ Ventilação natural / Sensação térmica } \\
\hline \multicolumn{2}{|c|}{$\begin{array}{c}\text { Nível de ansiedade / de depressão / de preocupação em contaminar-se / de estresse constante, fácil } \\
\text { irritabilidade }\end{array}$} \\
\hline \multicolumn{2}{|c|}{ Dificuldade de adaptar à rotina de ficar em casa / de conseguir/pedir ajuda } \\
\hline \multicolumn{2}{|c|}{ Aumento de gastos com água / de gastos com energia / de gastos com alimentação } \\
\hline \multicolumn{2}{|c|}{ Conflitos com familiares devido à falta de espaço / com os vizinhos } \\
\hline Dificuldade em a & um novo emprego \\
\hline
\end{tabular}

Em função das restrições decorrentes da pandemia, o questionário foi idealizado na ferramenta googleforms e distribuído via web de forma irrestrita, alcançando públicos de variadas classes sociais, econômicas e culturais e distintas localizações no Brasil. Essa ampliação do recorte da amostra foi intencional no sentido de oportunizar um levantamento mais expressivo e abrangente, podendo demonstrar situações de moradias distintas e respostas em diferentes contextos.

O questionário foi disponibilizado nas redes sociais do grupo [MORA] para coleta durante os meses de julho a setembro de 2020 na qual foram obtidas 468 respostas. Vale reforçar que a pesquisa foi estruturada em duas fases: 1 . Consulta com público irrestrito (com amostragem mínima de 188 respostas), realizada via web de forma ampla e aleatória, alcançando públicos de variadas classes sociais, econômicas e culturais e distintas localizações no Brasil e 2 . Consulta com público específico (com amostragem de 188 respostas) em estudo de caso já definido na pesquisa maior de habitações de interesse social (aprovada pelo Conselho de Ética em Pesquisa - CEP, protocolo no 20239019.5.0000.5152). Essa segunda fase está em desenvolvimento e deverá ser publicada em outro artigo científico.
Quadro 1. Perguntas componentes do questionário "Impactos de COVID-19 na Habitação.

Fonte: Autores, 2020 


\section{PRINCIPAIS RESULTADOS}

Na SEÇÃo 1 (dados gerais), foram obtidos dados que configuraram o perfil do entrevistado, predominantemente do sexo feminino (68\%), com predominância de idades entre 20 e 40 anos, mas com amostras de todas as faixas de idade (entre 10 e 80 anos). A grande maioria possuía escolaridade de pós-graduação completa $(41,7 \%)$, seguidos de superior incompleto $(21,2 \%)$ e superior completo $(22 \%)$. A renda média mensal foi uma amostragem bem variada, com predomínio entre 3 a 6 salários mínimos (25,8\%), seguidos de mais de 15 salários mínimos (23,3\%). Não havia moradores idosos em 70,3\% das casas. Esses dados demonstram que o público mais vulnerável economicamente não participou dessa primeira coleta, sendo sua participação planejada para etapas posteriores da pesquisa na qual consultas específicas serão realizadas.

Sobre as condições de moradia, em 50,2\% dos casos o núcleo familiar era composto por 3 ou 4 pessoas, seguidos de 40,3\% composto por 1 a 2 pessoas, demonstrando a predominância de entrevistados com núcleos familiares menores. Também se observou a predominância de residências próprias quitadas $(55,1 \%)$, seguida de $26,5 \%$ de residências alugadas, além de $57 \%$ morarem em casas, enquanto $43 \%$ em apartamentos. Já 69,3\% residem em loteamentos convencionais, enquanto $26,3 \%$ residem em condomínios fechados e $4,2 \%$ em conjuntos residenciais populares. Sobre a relação da quantidade de cômodos também se obteve uma amostragem variada, com predomínio de $22,7 \%$ tendo 5 cômodos (considerados aqui como salas e dormitórios apenas). 87,5\% alegaram possuir quintal, varanda e/ou sacada em suas residências.

Em relação à pandemia de COVID-19, 62,5\% responderam que alguém do grupo familiar está no grupo de risco da doença. Até o presente momento, possui caso confirmado em 14,6\% dos entrevistados, com apenas 1,1\% relatando óbito no grupo familiar. Já 2,8\% alegaram não estar fazendo nenhum tipo de medida preventiva, contrastando com os outros $97,2 \%$ respondidos. $54,8 \%$ continuam nos mesmos empregos recebendo os mesmos salários $(20,1 \%$ trabalhando no local e $34,7 \%$ trabalhando em home office), $20,6 \%$ continuam nos mesmos empregos recebendo menos ( $7 \%$ trabalhando no local e 13,6\% trabalhando em home office) e 4,2\% estão desempregados devido à pandemia de COVID-19. 0 tempo de permanência em casa antes do isolamento social era em sua maioria de 6 a 12 horas $(54,7 \%)$ e durante o isolamento social aumentou para 18 a 24 horas $(84,5 \%)$. Esse último conjunto de dados demonstra que de fato as pessoas entrevistadas têm permanecido em casa durante a pandemia.

A partir da análise dos dados da SEÇÃo 2 (nível de satisfação e comparativo antes e durante a pandemia), foram elencados seis principais aspectos da habitação nos quais o impacto da pandemia se faz presente de forma significativa. Tais aspectos demonstram, de certa forma, a baixa resiliência das moradias, indicando limitações na sua capacidade de se adaptar aos hábitos e protocolos decorrentes da pandemia de COVID-19.

Os dados foram organizados e analisados de forma comparativa para casas térreas e apartamentos. Isso porque observou-se que, quase na totalidade dos dados, o impacto da pandemia de Covid-19 nos apartamentos foi maior, representado pelos ampliados níveis de insatisfação dos quesitos avaliados em relação aos níveis apontados pelos moradores das casas. A seguir serão detalhados os principais aspectos da moradia e dos modos de vida impactados pela pandemia. 


\section{O TRABALHO/ESTUDO EM CASA}

Uma das questões mais impactadas pela pandemia foi sem dúvida a intensificação do trabalho e das atividades de ensino/estudo na moradia. Movimento esse que já se figurava entre as transformações do habitar em consolidação, acabou por se tornar uma regra em função do isolamento social e da quarentena (MENEZES; JANSEN, 2020). Em relação a esse aspecto, inúmeros desdobramentos podem ser percebidos a partir da adaptação necessária ao trabalho/ensino remoto a moradia como: (i) a qualidade funcional dos espaços para seu atendimento, (ii) a necessidade de uma ergonomia adequada, (iii) a necessidade de privacidade em relação aos membros da família, (iv) e infraestrutura necessária para a sua realização, (v) a conectividade para garantir o contato virtual com as pessoas, (vi) a dualidade entre a multifuncionalidade $\mathrm{x}$ monofuncionalidade dos espaços, (vii) novos usos para lugares pouco usados, (viii) a necessidade do apoio de adultos às crianças em ensino remoto, e (ix) a necessidade de espaços de estocagem decorrentes de todas as mudanças indicadas anteriormente. A ausência de tais qualidades atestou a pouca resiliência do ambiente construído em se adaptar aos impactos percebidos. Neste tópico, pode-se observar que há contextos diversos, como de pessoas que voltaram para casa, para trabalhar e estudar e pessoas que perderam seus empregos e começaram a trabalhar na informalidade demandando diferentes necessidades.

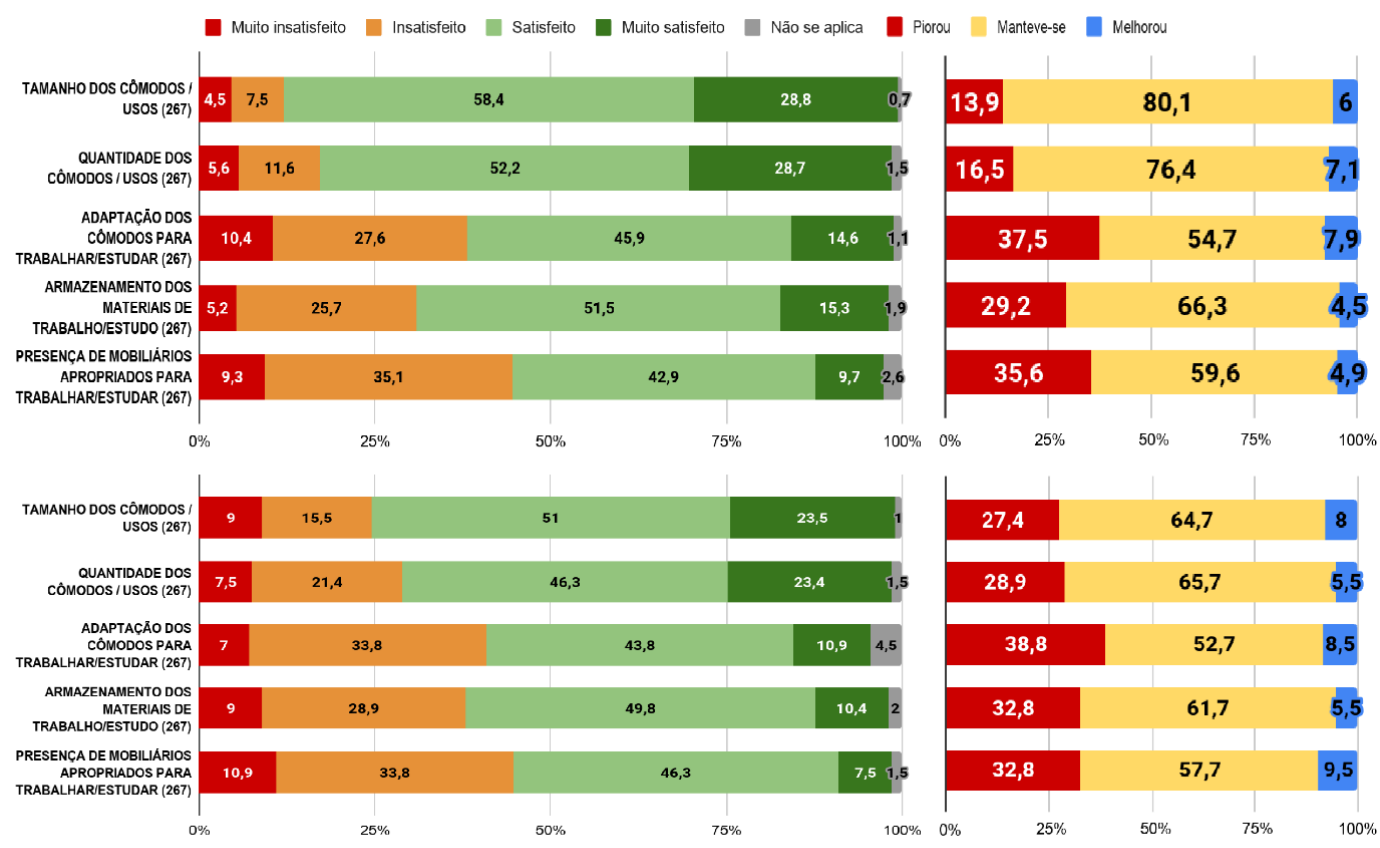

Com relação às respostas obtidas no questionário (Figura 2), verifica-se que as maiores insatisfações versam sobre a presença de mobiliários apropriados para trabalhar/estudar onde $44,4 \%$ dos respondentes moradores de casas e $44,7 \%$ de apartamentos mostraram-se insatisfeitos ou muito insatisfeitos, em conseguinte, 35,6\% (casas térreas) e 32,8\% (aptos) disseram que no momento pandêmico essa satisfação com relação aos mobiliários piorou, e apenas 4,9\% (casas térreas) e 9,5\% (aptos) notaram uma melhoria nesse aspecto. 0 mesmo ocorre com a adaptação dos cômodos para trabalhar/estudar onde 38\% dos respondentes moradores de casas e $40,8 \%$ de apartamentos mostraram-se insatisfeitos ou muito insatisfeitos, em conseguinte, 37,5\% (casas térreas) e 38,8\% (aptos) disseram que no momento pandêmico a satisfação piorou. Diante da quantidade de cômodos frente aos usos nas moradias, $20,1 \%$ (casas térreas) e 30,9\% (aptos) apontaram sua insuficiência, ainda nesse sentido 19,1\% (casas térreas) e 30,8\% (aptos) disseram que essa situação se agravou durante
Figura 2. Gráficos da seção 2 do questionário com informações relativas ao trabalho em casa - nível de satisfação e comparativo antes e durante a pandemia, com os dados das casas e dos aptos, respectivamente

Fonte: Autores, 2020 
o isolamento social. Também se observou que em relação ao armazenamento dos materiais de trabalho/estudo, 30,9\% (casas térreas) e 37,9\% (aptos) se mostraram insatisfeitos, situação essa que também foi agravada pelo isolamento $(29,2 \%$ casa térreas e $32,8 \%$ aptos indicaram que a situação piorou).

O trabalho e o estudo em casa e, portanto, a permanência ampliada no espaço doméstico, ressaltou patologias funcionais/espaciais e a pouca resiliência do ambiente construído, anteriormente não percebidas pelos usuários. A insatisfação quanto ao espaço físico da moradia foi acentuada em função da necessidade da realização e sobreposição de diversas atividades anteriormente exercidas no espaço público (cidade), que no momento pandêmico passaram a realizar-se no espaço privado (dentro de casa), muitas vezes dividido com outras pessoas.

\section{A INFLUÊNCIA/NECESSIDADE DA TECNOLOGIA}

Movimento que já se intensificava nas últimas décadas, a presença da tecnologia no espaço doméstico demonstra-se, no cenário da pandemia, como uma necessidade. Nunca foi tão importante possuir equipamentos como computadores e smartphones com acessos à internet. Até as televisões, que já estavam de certa forma em desuso, tornaram-se as vedetes da casa, munidas agora de acesso às redes wifi e aos canais digitais. A partir disso, inúmeros desdobramentos são percebidos na configuração dos espaços, além da necessidade de infraestruturas adequadas a essas novas demandas. A flexibilidade, tanto espacial como das instalações e equipamentos, no ambiente doméstico torna-se um atributo fundamental para a resiliência da moradia, facilitando a inserção e a adaptação de novas tecnologias no ambiente.

As atividades que normalmente acontecem no ambiente urbano, passam a ter uma presença significativa dentro da casa. 0 acesso ao comércio, à cultura e ao lazer desloca-se do espaço físico para ocupar, de forma predominante, as telas dos smartphones. As distâncias se encurtam e os pontos de acesso à energia elétrica para que os equipamentos funcionem elevaram o status de importância dentro das casas. Infelizmente essa realidade se difere muito em cada contexto social (BITTENCOURT, 2020). Nesse sentido a inclusão digital se coloca mais uma vez, e agora de forma definitiva, como necessidade frente a diminuição das desigualdades sociais e das vulnerabilidades do país.

Segundo o IBGE (2018) 79,1\% dos lares brasileiros são atendidos por internet, esse número é ainda maior quando analisado isoladamente o percentual de lares com acesso a internet pelo smartphone, 99,2\% atingindo quase a totalidade. Durante o isolamento social o acesso a aparelhos eletrônicos e internet foi para muitos uma ferramenta crucial para o desenvolvimento de atividades remotas ou até mesmo para o entretenimento (FIOCRUZ, 2020).

\section{OS PADRÕES DE CONSUMO E CONSCIÊNCIA AMBIENTAL}

A permanência em casa funciona como uma espécie de lupa para determinados problemas domésticos, notadamente em relação aos padrões de consumo e a consequente consciência ambiental. Pode-se observar que há um aumento na produção de lixo das moradias, além de um impacto nas contas de energia, água, e alimentação, que se mostraram em elevação. Ao se verem em casa, as pessoas passam a observar hábitos sustentáveis e valorizar áreas verdes e abertas como sacadas e quintais, um refúgio mesmo que por dentro de muros e guarda-corpos trazendo uma certa sensação de abertura com a cidade. Nesse contexto, também podemos observar o questionamento do que realmente é relevante em termos de consumo e necessidades. 


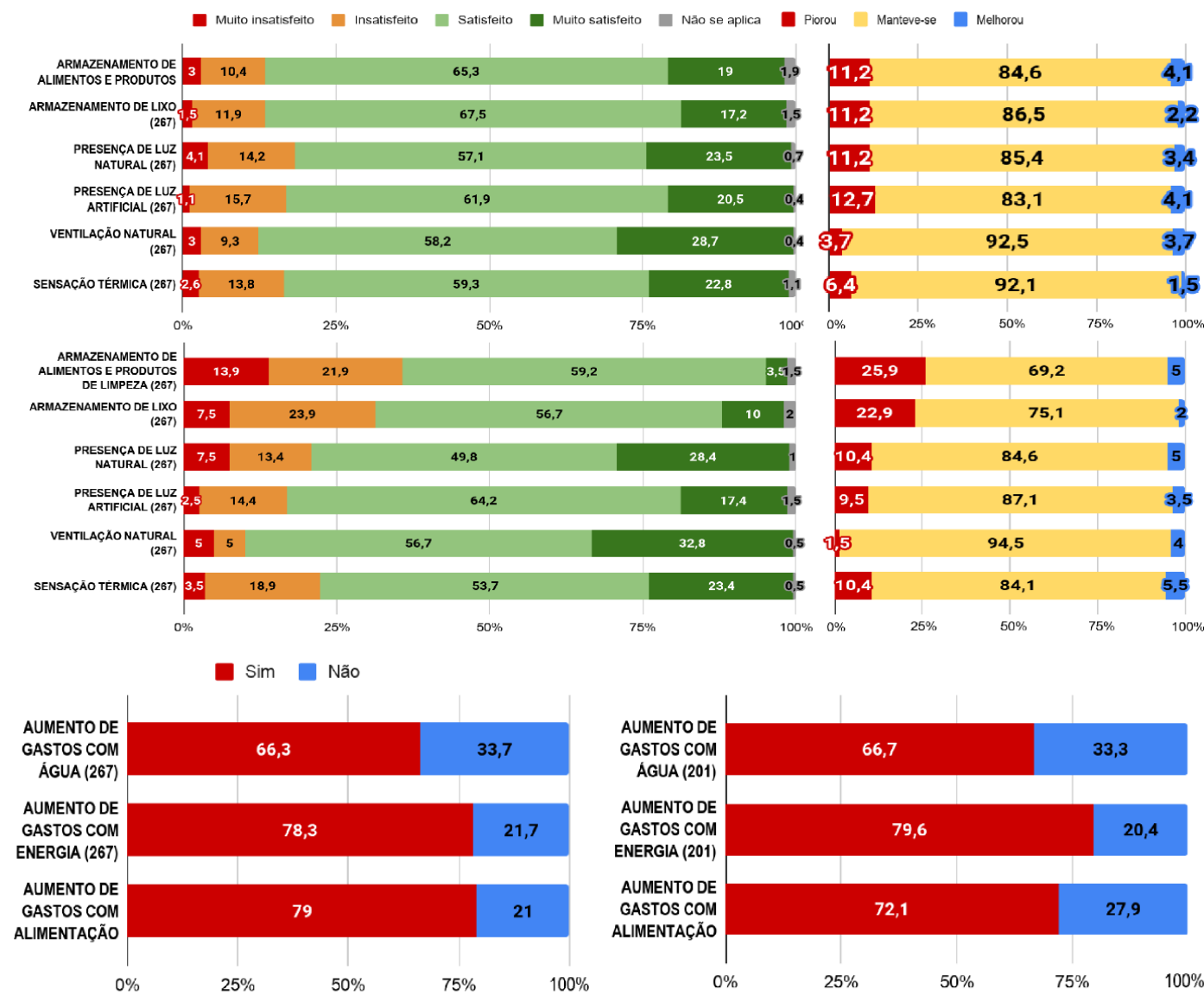

Condicionados a ficarem em casa, muitas pessoas apontam que durante o momento pandêmico o espaço para armazenamento de alimentos e produtos de limpeza, e o armazenamento de lixo não foi suficiente, sendo $11,2 \%$ e $11,2 \%$ respectivamente em casas térreas, $25,9 \%$ e $22,9 \%$ respectivamente em apartamentos (Figura 3), demonstrando a baixa capacidade dos ambientes de se adaptarem aos impactos percebidos. Ainda nesse contexto, um número expressivo de usuários notou aumento de gastos com água (66,3\% - casas térreas, 66,7\% aptos), aumento de gastos com energia elétrica (78,3\% - casas térreas, 79,6\% - aptos) e aumento com alimentação (79\% - casas térreas, 72,1\% - aptos) (Figura 4).

Em relação ao conforto ambiental dessas residências, 4,1\% em casas e 7,5\% em apartamentos alegaram não possuir presença de luz natural suficiente, tendo piorado em $11,2 \%$ dos casos em casas térreas e em 10,4\% em apartamentos. A presença de luz artificial manteve-se insuficiente em $3,6 \%$ dos casos (1,1\% em casas e 2,5\% em aptos), piorando em $12,7 \%$ em casas e 9,5\% em apartamentos. Nesse sentido, grande parcela dos pesquisados afirmaram não terem observado melhora ou piora quando questionados sobre a presença de luz e ventilação natural, sendo as casas: $84,6 \%$ e $94,5 \%$ (respectivamente) e apartamentos: $85,4 \%$ e $92,5 \%$ (respectivamente). Acreditamos que tal resultado se justifica devido ao bom nível das habitações avaliadas, constatado a partir dos níveis de renda declarados, predominantemente de 3 a 6 salários mínimos (25,8\%) e renda de mais de 15 salários mínimos (23,3\%).

A ventilação natural e a sensação térmica foram insuficientes em 5,6\% das casas e 8,5\% dos apartamentos, tendo piorado em 10,1\% nas casas e 11,9\% nos apartamentos (Figura 3). Essa atual insatisfação com o conforto ambiental das residências pode configurar uma preocupação com a arquitetura bioclimática. A percepção mais aguçada que as pessoas estão tendo sobre a necessidade de se ter luz e ventilação naturais, valoriza os atributos da arquitetura
Figura 3. Gráficos da seção 2 do questionário. Informações relativas aos padrões de consumo e consciência ambiental - nível de satisfação e comparativo antes e durante a pandemia, com os dados das casas e dos apartamentos, respectivamente

Fonte: Autores, 2020

Figura 4. Gráficos da seção 2 do questionário. Padrões de Consumo e Consciência Ambiental, com os dados das casas e dos apartamentos, respectivamente

Fonte: Autores, 2020 
bioclimática, além da sustentabilidade da residência, ressaltando a consciência ambiental frente à edificação.

\section{OS NOVOS USOS E HÁBITOS}

Palco de diversos usos, a moradia, no contexto da pandemia, passa a intensificar novas e variadas demandas (CARLOS, 2020). Além das demandas do trabalho e do estudo em casa, os hábitos de higiene são significativamente alterados. A porta da casa se intensifica como o limite e a barreira entre os cenários interno/limpo/seguro e o externo/sujo/perigoso. A fim de preservar a segurança dos moradores tudo que chega de fora precisa ser higienizado (uma espécie de ritual): sapatos que não entram em casa, produtos de supermercado, pedidos por delivery, passam a ter atenção especial, pois carregam a premissa de que são provenientes do mundo exterior contaminado. E a habitação passa a ser um espaço na qual a preocupação com a limpeza se intensifica em um universo de gestão compartilhada onde todos os moradores auxiliam.

Nesse cenário intradomiciliar, hábitos como cozinhar e fazer pequenas reformas em casa se tornam mais evidentes. Também as atividades, anteriormente pública e coletivas, como exercitar-se, brincar ou mesmo fazer aulas de artes, músicas, etc., são incorporadas ao universo privado, demandando adequações funcionais nos ambientes domésticos. A cidade se desloca, temporariamente, para dentro da casa, impactando a qualidade dos espaços e dos usos.

Figura 5. Gráficos da seção 2 do questionário. Informações relativas aos novos hábitos e usos de consumo - nível de satisfação e comparativo antes e durante a pandemia, com os dados das casas e dos apartamentos, respectivamente

Fonte: Autores, 2020

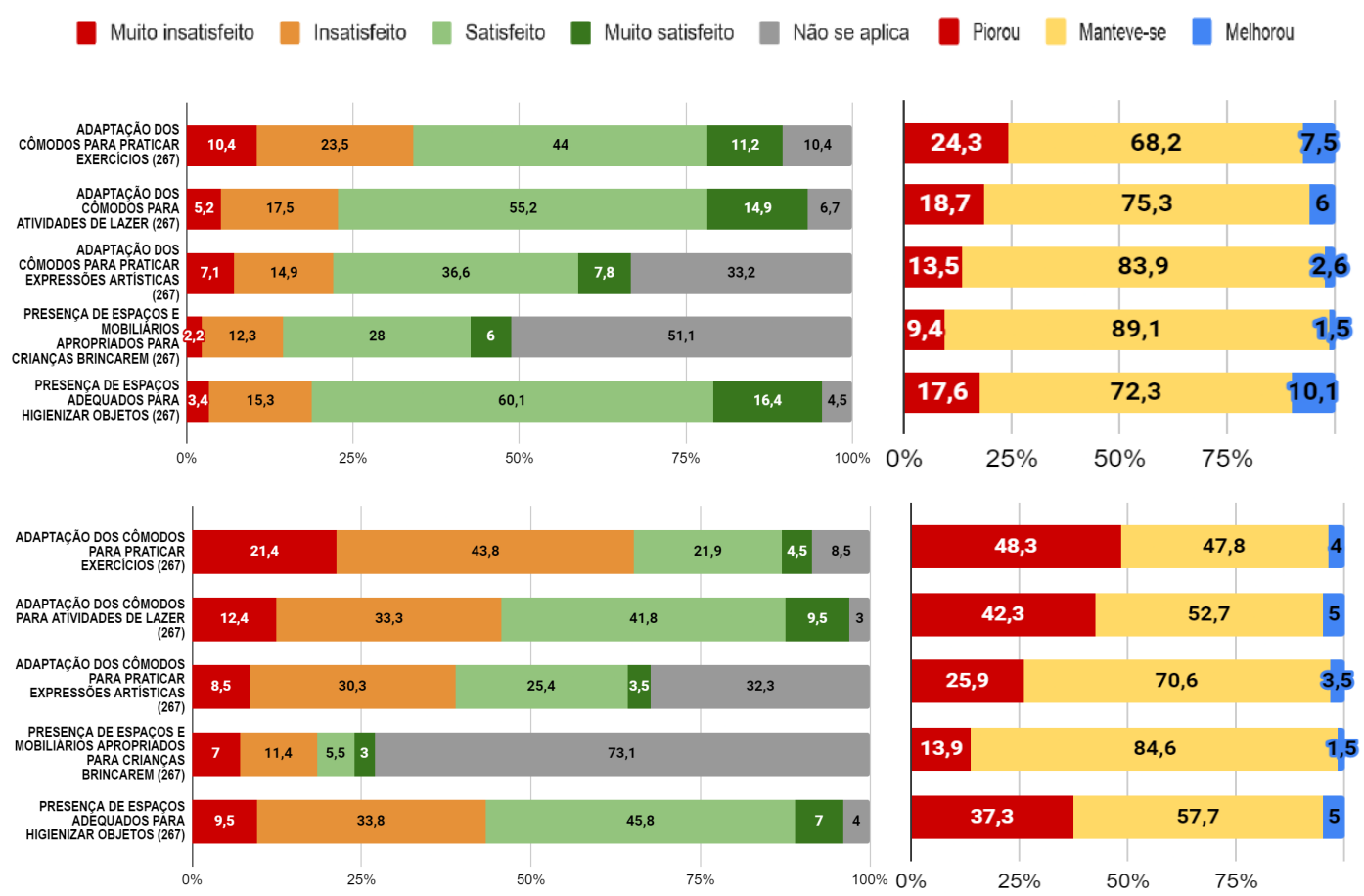

Nessa continuidade, as pessoas foram condicionadas a adaptarem suas habitações para atender esses novos usos, entretanto 33,9\% (casas térreas) e 65,2\% (aptos) se mostraram insatisfeitos ou muito insatisfeitos com as adaptações dos cômodos para praticar exercícios e que durante a pandemia essa situação se agravou (24,3\% - casas térreas, 48,3\% aptos). Essas insatisfações são recorrentes em outras esferas como em adaptações dos cômodos para atividades de lazer, adaptações dos cômodos para praticar expressões artísticas, a carência na presença de espaços e mobiliários apropriados para crianças brincarem, e a falta de presença de espaços adequados para higienização de objetos conforme observado na figura 5 . 
É importante destacar a presença das respostas "não se aplica" no questionário, onde a maior porcentagem delas foi observada nas questões referentes a adaptação dos cômodos para praticar expressões artísticas (33,2\% nas casas e 32,3\% nos apartamentos) e presença de espaços e mobiliários apropriados para crianças brincarem $(51,1 \%$ nas casas e $73,1 \%$ nos apartamentos), demonstrando que os avaliados não utilizam suas residências para tal ação e/ou devido à ausência de crianças nas residências, no segundo caso.

A presença de espaços adequados para higienizar objetos se mostrou insatisfatória em 18,7\% (casas térreas) e 43,3\% (aptos), tendo piorado em 17,6\% nas casas e 37,3\% em apartamentos. Esse atributo difere bastante entre a casa e o apartamento, sendo no primeiro menos problemático que no segundo, bastante problemático, o que indica a possível adaptação de cômodos nas residências térreas para essa função, enquanto em apartamentos isso não é possível, causando grande dificuldade aos moradores quando se trata em higienizar os objetos que vem da rua.

No quesito "adequação aos novos usos e hábitos", verifica-se que as moradias avaliadas possuem configurações espaciais tradicionais, baseadas em modelos tripartidos de morar e espaços reduzidos, demonstrando, mais que em qualquer outro quesito, pouca resiliência, e, portanto, baixa capacidade de se adaptar aos impactos impostas pela pandemia. A adaptação às novas demandas e impactos oriundos da sobreposição de pessoas e atividades nas moradias potencializou tensões estabelecidas no âmbito doméstico trazendo à tona problemas funcionais das habitações (BARBOSA e NEIS, 2020; VILLA et. al., 2020).

\section{A RELAÇÃO COM A CIDADE/BAIRRO/VIZINHOS}

Os impactos do isolamento social decorrentes da pandemia de Covid-19 influenciam mudanças de comportamento intra e extradomiciliares. A necessidade de internalizar e privatizar ações anteriormente realizadas na esfera pública e coletiva traz consequências modificando as relações entre a habitação e a cidade. A ausência do espaço público reforçou a importância dos espaços abertos das moradias através de suas varandas, sacadas e quintais. Nesses espaços intersticiais, quase de transição, encontrou-se significados da vida pública: olhar para fora, se conectar cuidadosamente com o exterior, tomar sol, respirar o ar mais puro, conversar com vizinhos, plantar e colher, tocar um instrumento. Ações quase que representativas de um mundo coletivo/público inseguro que pretende um dia ser normal.

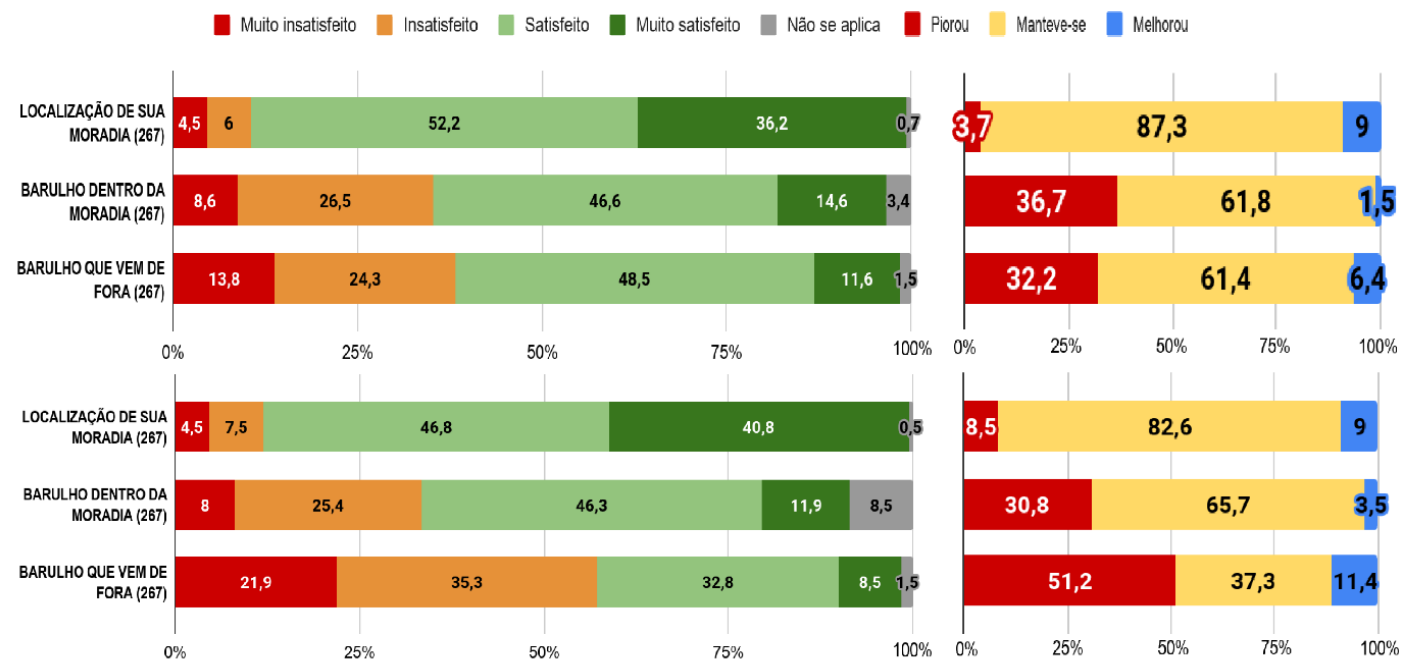

Figura 6. Gráficos da seção 2 do questionário. Informações relativas a relação com a cidade, bairro e vizinhos nível de satisfação e comparativo antes e durante a pandemia, com os dados das casas e dos apartamentos, respectivamente

Fonte: Autores, 2020 
Figura 7. Gráficos da seção 2 do questionário. Informações relativas a relação com a cidade, bairro e vizinhos, com os dados das casas e dos apartamentos, respectivamente

Fonte: Autores, 2020
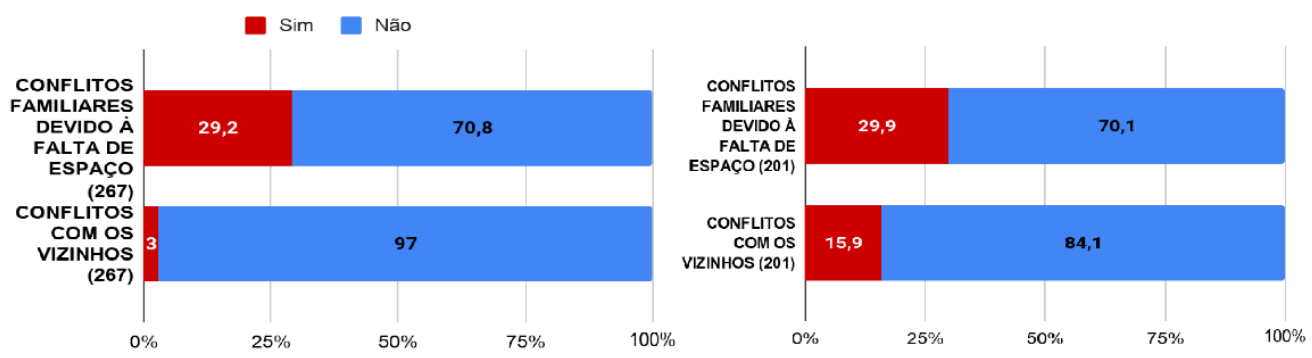

Sobre o nível de satisfação do morador em relação a localização de sua moradia, observamos quase uma totalidade de satisfeitos e muito satisfeitos, com $52,2 \%$ e $36,2 \%$ (casas térreas), e $46,8 \%$ e $40,8 \%$ (aptos) respectivamente. Apenas 3,7\% (casas térreas) e 8,5\% (aptos) disseram ter notado uma piora em relação a localização (Figura 6).

Em uma escala menor, pode ser observado a percepção de barulho na moradia, onde estão muito insatisfeitos $8,6 \%$ em casas e $8 \%$ em apartamentos, piorado em $36,7 \%$ (casas) e $30,8 \%$ (aptos), tendo essa percepção com o barulho que vem de fora muito pior, onde os muito insatisfeitos somam $13,8 \%$ nas casas e $21,9 \%$ nos apartamentos, com uma piora significativa de $32,2 \%$ (casas) e $51,2 \%$ (aptos). Essa análise diz muito sobre a nova percepção interna e externa nas edificações, com as pessoas passando mais tempo em suas moradias, notam mais o barulho que causam e o que é causado na vizinhança.

A relação com membros internos e externos é observada na figura 7, nas quais 29,2\% (casas) e $29,9 \%$ (aptos) das unidades passaram a apresentar conflitos familiares internos devido à falta de espaço tão como a existência de conflitos com os vizinhos em 3\% (casas) e 15,9\% (aptos) das unidades avaliadas. Novamente, a insatisfação de moradores de apartamentos é predominante, o que ressalta o maior impacto da pandemia COVID-19 nessas pessoas.

Ademais, verificamos que mesmo com um retorno gradual das atividades, frente a vacinas e tratamentos mais eficientes do COVID-19, muitas ações públicas e coletivas terão de ser revisadas em função de condutas rígidas de segurança, demandando novos desenhos espaciais. Finalmente, ao considerar todos os aspectos anteriores verificamos um movimento incipiente e gradual do êxodo urbano, já que alguns preferem morar distantes dos problemas urbanos face à possibilidade de levarem uma vida mais natural mantendo a conexão com a cidade de forma remota e virtual. Do ponto de vista da unidade habitacional, atesta-se a necessidade de um redesenho mais que necessário de seus espaços e equipamentos, contemplando novas demandas e expectativas no sentido de tornar a casa cada vez mais resiliente aos atuais e futuros impactos. Novamente a resiliência na habitação, obtida principalmente pelos atributos da flexibilidade e da adequação ambiental e climática, nos parece ser uma qualidade urgente e necessária no desenho da habitação contemporâneav .

\section{AS NOÇÕES DE PRIVACIDADE E INTERAÇÃO}

Novas noções de privacidade e interação no espaço doméstico também são percebidas no contexto do isolamento social decorrentes da pandemia de COVID-19. 0 uso e a influência da tecnologia nos modos de vida, de certa forma, desde o final do século XX, evidenciaram novas noções de privacidade e interação nas habitações, potencializadas pelo cenário atual. A mobilidade dos equipamentos celulares e computadores e a provisão de redes wifi, intensificou a noção de privacidade, deslocando-a para o corpo. Se anteriormente o privado esteve durante séculos atrelado ao espaço físico do quarto, agora a simples presença de um equipamento o configura. Novas janelas virtuais se abrem e vão aos poucos reconfigurando as noções de privacidade do indivíduo. 
No ambiente doméstico do isolamento, muitas vezes determinadas atividades de trabalho e estudo que exigem concentração ou mesmo interação ficam comprometidas em função do formato familiar, do número de membros e do tipo de organização espacial da casa. Mais do que nunca a flexibilidade foi tão necessária no sentido de garantir maior resiliência aos espaços e a consequente qualidade das ações, sem comprometer a privacidade e a interação necessária de cada família.

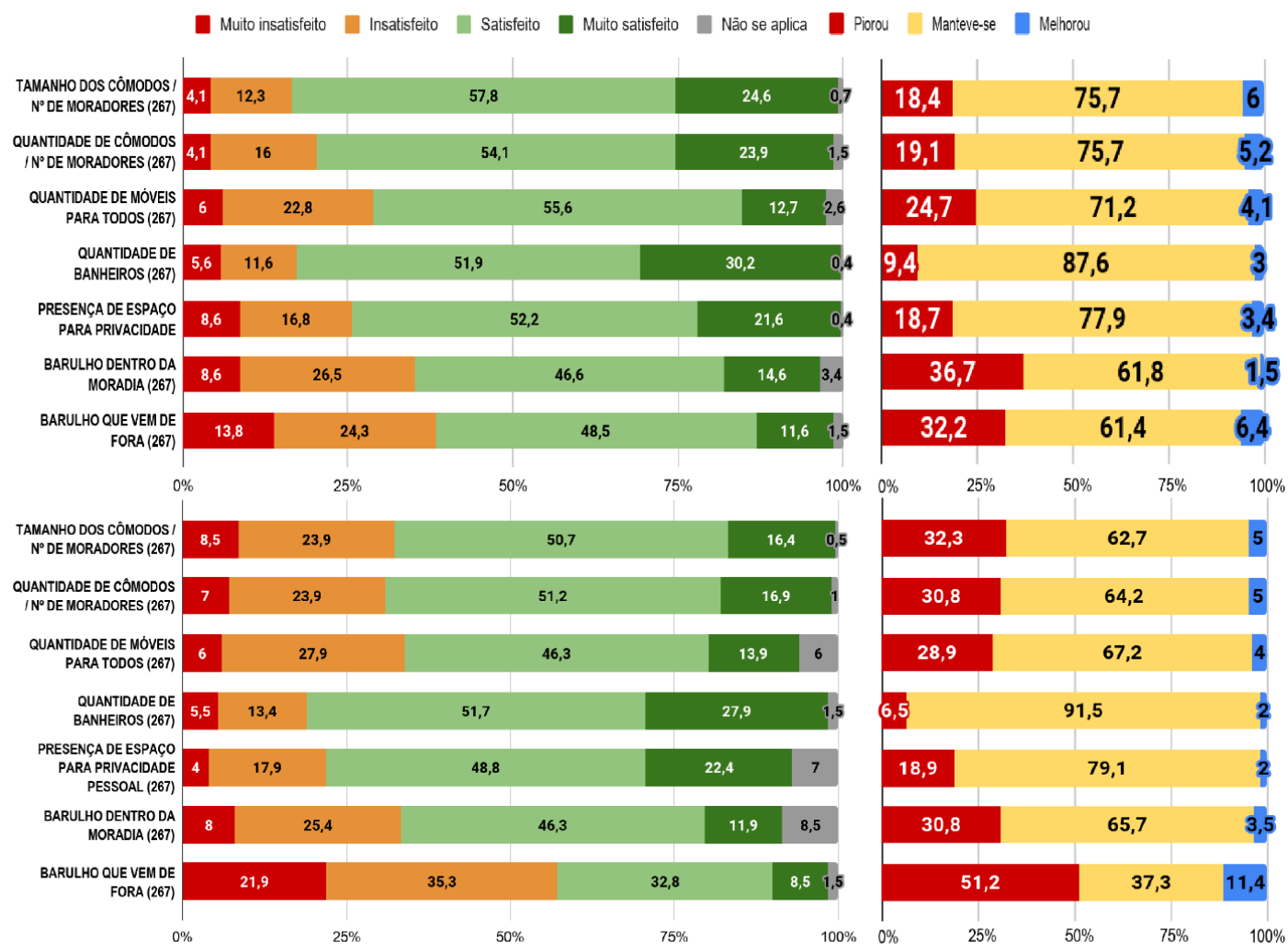

Nesse sentido, foi investigado o nível de satisfação em relação aos aspectos físicos da edificação no que diz respeito à privacidade. Em relação ao tamanho dos cômodos em relação ao número de moradores $16,4 \%$ (casas térreas) e 32,4\% (aptos) se declararam insatisfeitos ou muito insatisfeitos. E no momento pandêmico notaram uma piora na situação: 18,4\% (casas térreas) e 32,3\% (aptos) relataram a insuficiência da quantidade de cômodos em relação ao número de moradores. Esta, também foi apontada como insatisfatória ou muito insatisfatória, sendo 21,1\% (casas térreas) e 30,9\% (aptos). Além disso, 19,1\% (casas térreas) e 30,8\% (aptos) relataram que essa insuficiência se agravou no momento de isolamento social (Figura 8).

Várias outras questões relacionadas à interação dos moradores em tempos de pandemia foram observadas, conforme a figura 7, muitas delas com altos níveis de insatisfação. A interação entre moradores e a relação com os ambientes domésticos foram colocadas em xeque, a partir do momento em que a casa passou a ser o local no qual as pessoas passam a maior parte do tempo, ampliando seu tempo de convivência com familiares, potencializados muitas vezes pela falta de espaço. Assim atestam os dados: 29,2\% dos moradores de casas térreas e 29,9\% dos moradores de aptos declararam ter conflitos familiares devido à falta de espaços em suas moradias.
Figura 8. Gráficos da seção 2 do questionário. Informações relativas às noções de privacidade e interação nível de satisfação e comparativo antes e durante a pandemia, com os dados das casas e dos apartamentos, respectivamente

Fonte: Autores, 2020 


\section{CONSIDERAÇÕES FINAIS}

Com o objetivo de discutir os dados coletados e seus possíveis rebatimentos na arquitetura, refletindo sobre as problemáticas decorrentes do isolamento social imposto pela pandemia, os dados analisados nesta pesquisa e em conseguinte os resultados aqui descritos são apresentados como provocações e reflexões. Ainda imersos na realidade pandêmica, somos convidados a investigar e provocar um olhar crítico sobre um processo ainda em curso e de grandes incertezas. Processo esse que se mostra muito diverso em outros contextos na qual realidades sociais, culturais e econômicas são diferentes. Mesmo assim, entendemos necessária a reflexão e a adequada aproximação científica ao problema.

Nesse sentido, as reflexões apresentadas no artigo retratam a realidade e a percepção de uma amostra da população, explicitada na seção 1 dos resultados, podendo ser reconhecida em diversos contextos nacionais e internacionais similares. A partir de análises dos dados obtidos, pode ser observado a distinção necessária entre o exterior - contaminado e inseguro -, com o interior - limpo e seguro. Com o isolamento social, muitas pessoas tiveram que adaptar seus espaços de moradia para trabalhar, estudar, praticar exercícios, exercer atividades de lazer, entre outros, testando a resiliência de suas moradias.

Tensões foram estabelecidas no âmbito doméstico no sentido da adaptação às novas demandas e impactos oriundos da sobreposição de pessoas e atividades nas moradias. Nesse contexto, a pandemia trouxe alguns problemas para as habitações e evidenciou outros já conhecidos. Mais do que nunca, a resiliência no ambiente construído, caracterizada pelas qualidades necessárias como a funcionalidade espacial, a ergonomia, a privacidade, a infraestrutura e conectividade, a multifuncionalidade, a necessidade de espaços adequados de estocagens e a flexibilidade espacial, se mostram de grande valia nas moradias no momento em que vivemos. Alguns usos e hábitos se observaram mais frequentes durante a pandemia, como o ritual de higienização, novos fluxos e isolamentos, novos hábitos (cozinhar, plantar, cuidar da casa, etc.), gestão compartilhada do espaço doméstico, demandando um redesenho necessário. Além disso, o consumo necessário e local, a quantidade de resíduos gerada, o aumento gasto com alimentação, água e energia e a valorização de áreas verdes podem funcionar como indutores para o despertar de uma nova consciência ambiental.

Por outro lado, tais demandas percebidas podem, no futuro muito próximo, gerar a necessidade de maiores e mais qualificados espaços internos para se viver, providos de áreas verdes ou espaços ao ar livre. As respostas poderão desencadear, por exemplo, uma expansão urbana periférica ainda maior, além de transformar o campo da construção civil com a construção de apartamentos e casas maiores, com hall de entrada para higienização e tantas outras alterações que se veem ausentes e muito necessárias nas construções atuais.

Frente a esse cenário, verifica-se que as inadequações e impactos percebidos nas habitações apresentados na pesquisa reforçam velhos e conhecidos problemas como a baixa qualidade espacial e ambiental dos espaços privados, coletivos e públicos, a manutenção de modelos tripartidos de morar com áreas bastante reduzidas, a ausência de atributos de resiliência, entre outros. Assim como reforça as vulnerabilidades das habitações destinadas aos extratos sociais mais baixos, reforçando nossas enormes desigualdades sociais.

Finalmente destaca-se a relevância de trabalhos avaliativos que objetivam compreender de forma sistematizada as necessidades e anseios dos moradores e a montagem de bancos de dados para promover a ampliação da qualidade e da resiliência da habitação, notadamente em cenários extremos, como esse que estamos atravessando. 


\section{Agradecimentos}

Agradecemos à Universidade Federal de Uberlândia - UFU, à Coordenação de Aperfeiçoamento de Pessoal de Nível Superior - CAPES e ao Conselho Nacional de Desenvolvimento Científico e Tecnológico - CNPq pelo apoio recebido para o desenvolvimento dessa pesquisa.

\section{Referências Bibliográficas}

ARUP; The Rockefeller Foundation. City Resilience Index, 2015, 16 p. Disponível em: <https://www.arup.com/perspectives/publications/research/section/cityresilience-index> Acesso em 01 fev. 2020.

BARBOSA, O. L.; NEIS, A. C. Habitação em meio à pandemia: Um debate necessário. Revista Pet Economia UFES, v. 1, n. 1, p. 20-22, 2020.

BITTENCOURT, R. N. Pandemia, isolamento social e colapso global. Revista Espaço Acadêmico, v. 19, n. 221, p. 168-178, 2020.

CARLOS, A. F. A. A "revolução" no cotidiano invadido pela pandemia. In: CARLOS, A. F. A. (Org.). COVID-19 e a crise urbana. São Paulo: FFLCH/USP, 2020. https://doi.org/10.11606/9786587621036.

COLE, R. J. Building environmental assessment methods: redefining intentions and roles. Building Research \& Information, v.33, n. 5, p. 455-467, 2005. DOI: 10.1080/09613210500219063.

https://doi.org/10.1080/09613210500219063.

ELIAS-TROSTMANN, K.; CASSEL, D.; BURKE, L.; RANGWALA, L. Mais forte do que a tempestade: aplicando a avaliação de resiliência comunitária urbana aos eventos climáticos extremos. Documento de Trabalho. Washington, DC: World Resources Institute. Disponível online em <https://www.wri.org/publication/strongerthan-the-storm>. Acesso em fev. 2020.

FIOCRUZ. Fundação Oswaldo Cruz. O papel das redes sociais durante a pandemia. 2020. Escrito por Mayra Malavé. Disponível em: http://www.iff.fiocruz.br/index.php/8-noticias/675-papel-redes-sociais. Acesso em: 01 mar. 2021.

GARCIA, J. E; VALE, B. Unravelling Sustainability and Resilience in the Built Environment. Routledge, Londres, 2017.

GRUBER, A. Covid-19: o que se sabe sobre a origem da doença. Jornal da USP, 14/04/2020. Disponível em: https://jornal.usp.br/?p=314416. Acesso em: 02 mar 2021.

HASSLER, U; KOHLER, N. Resilience in the built environment. Building Research \& Information, 42:2, 119-129, 2014. DOI: 10.1080/09613218.2014.873593. https://doi.org/10.1080/09613218.2014.873593.

IBGE. Instituto Brasileiro de Geografia e Estatística. Acesso a internet. 2018. Disponível em $<$ https://biblioteca.ibge.gov.br/visualizacao/livros/liv101705_informativo.pdf>Acesso em 29 de outubro de 2020.

LEMOS, M. F. Sustentabilidade e Resiliência. In: III ENANPARQ. Arquitetura, Cidade e Projeto: uma construção coletiva, 2014, São Paulo. Anais do III ENANPARQ. Arquitetura, Cidade e Projeto: uma construção coletiva. São Paulo: ANPARQ. p. 1-14. 2014.

MALLORY-HILL, S.; PREISER, W. F. E.; WATSON, C. (edits). Enhancing Building Performance. Oxford, UK: WileyBlackwell, 330p, 2012.

MENEZES, R. C. de; JANSEN, A. C. The emergence and impacts of home office strategy during the pandemic scenario of COVID-19. In: International Journal of Advanced Engineering Research and Science (IJAERS). Vol-7, Issue-9, Sep- 2020. DOI: 10.22161/ijaers.79.6 https://dx.doi.org/10.22161/ijaers.79.6

New Urban Agenda. Habitat III, United Nations, 2017. Available at http://habitat3.org/wpcontent/uploads/NUA-English.pdf. Acessed 10 January 2018.

Gestão \& Tecnologia de Projetos 
ONO, R.; ORNSTEIN, S. W.; VILLA, S. B.; FRANÇA, A. J. G. L. Avaliação Pós-Ocupação: na arquitetura, no urbanismo e no design: da Teoria à Prática. São Paulo: Oficina de Texto, 2018.

Organização Pan Americana de Saúde. Folha informativa COVID-19 - Escritório da OPAS e da OMS no Brasil. Disponível em: https://www.paho.org/pt/covid19. Acesso em 26/10/2020.

PARREIRA, F. V. M. Estratégias de flexibilidade orientadas ao usuário como fator facilitador da Resiliência em Habitação de Interesse Social. - Uberlândia. 2019. 104 f. Memorial de Qualificação (Mestrado em Arquitetura e Urbanismo - Universidade Federal de Uberlândia, 2019.

PICKETT, S.T.A., MCGRATH, B., CADENASSO, M.L. \& FELSON, A.J. Ecological resilience and resilient cities, Building Research \& Information, 42:2, 143-157, 2014. DOI: 10.1080/09613218.2014.850600. http://dx.doi.org/10.1080/09613218.2014.850600.

QUAMMEN, D. Contágio: Infecções de Origem Animal e a Evolução das Pandemias. Epub: Companhia das Letras, 2020.

SANTOS, B. de S. A cruel pedagogia do vírus. Epub: Boitempo, 2020.

STEVENSON, F.; LEAMAN, A. Evaluating housing performance in relation to human behaviour: new challenges. Building Research \& Information, v. 38, n. 5, p.437-44, 2010. DOI: 10.1080/09613218.2010.497282. http://dx.doi.org/10.1080/09613218.2010.497282

STEVENSON, F. Housing fit for purpose: performance, feedback and learning. London: RIBA, 2019.

Sustainable Development Goals. General Assembly: Transforming our world: the 2030 Agenda for Sustainable Development, United Nations, 2015. Available at http://www.un.org/sustainabledevelopment/sustainabledevelopment-goals/. Acessed 10 January 2018.

Simone Barbosa Villa simonevilla@ufu.br

Gabriela Pereira Carneiro g.carneiro@ufu.br

Rodrigo Araujo Moraes rodrigoaraujomoraes @gmail.com

Nathalia Lya de Melo Carvalho nathalialya@yahoo.com.br
VAN DER VOORDT, T. J. M.; VAN WEGEN, H. B. R. Arquitetura sob o olhar do usuário. São Paulo: Oficina de Textos, 2013.

VILLA, S. B.; ORNSTEIN, S. W. (Org.) Qualidade ambiental na habitação: avaliação pós-ocupação. São Paulo: Oficina de Textos, 2013. p.359-378.

VILLA, S. B.; GARREFA, F., STEVENSON, F., SOUZA, A. R., BORTOLI, K. C. R., ARANTES, J. S., VASCONCELLOS, P. B., CAMPELO, V. A. Método de análise da resiliência e adaptabilidade em conjuntos habitacionais sociais através da avaliação pós-ocupação e coprodução. RELATÓRIO DE PESQUISA: Uberlândia: Universidade Federal de Uberlândia; Universidade de Sheffield, 2017, 393 p.

VILLA, S. B.; CARNEIRO, G. P.; CARVALHO, A. R. de L.; MARCHIOLLI, C. K. F.; PICCELLO, I.; BRITO, M. C. S.; REZENDE, M. G. de F.; MIRANDA, N. L.; CARRITI, R. G.; MORAES, R. A.; LIMA, S. C. P.; (AUTORES). Workshop Impacto da Covid-19 na habitação: Wks.doc. Relatório Final. Uberlândia: PPGAU, FAUeD, Universidade Federal de Uberlândia, 2020. Disponível em: <https://morahabitacao.files.wordpress.com/2021/09/relatoriofinal_workshop-covid-19_resumo.pdf>Acesso em: 30/10/2020/.

\section{Notas}

' Pesquisa em curso financiada pelo CNPq desenvolvida no [MORA]. Para maiores informações ver em: https://morahabitacao.com/pesquisas-em-andamento-2/ber home-resiliencia-no-ambienteconstruido-em-habitacao-social-metodos-de-avaliacao-tecnologicamente-avancados/

ii [MORA] Grupo de pesquisa da Faculdade de Arquitetura e Urbanismo e Design (FAUeD) da Universidade Federal de Uberlândia. Para maiores informações ver em:

https://morahabitacao.com/ 
iii Questionário Digital - Impactos da Pandemia COVID-19 na Habitação. Para maiores informações ver em:

https://docs.google.com/forms/d/e/1FAlpQLSd6zyw5YmaGNnrfSDxD7 rpaTmXtJx8ntpUu hQedBL 2LugBw/viewform

iv Relatório Final - Workshop "Impacto da Covid-19 na habitação". Para maiores informações ver em: https://morahabitacao.files.wordpress.com/2021/09/relatorio-final workshop-covid-

19 resumo.pdf

v Na pesquisa "[BER HOME] Resiliência no ambiente construído em habitação social: métodos de avaliação tecnologicamente avançados", financiada pelo CNPq, foram identificados os principais atributos facilitadores da resiliência: conforto ambiental, adequação ambiental, flexibilidade, acessibilidade, resistência, bem-estar e engajamento. 